\title{
British Thoracic Society Sarcoidosis study: effects of long term corticosteroid treatment
}

\author{
G J Gibson, R J Prescott, M F Muers, W G Middleton, D N Mitchell, C K Connolly, \\ B D W Harrison
}

\begin{abstract}
Background - Corticosteroids suppress disease activity in pulmonary sarcoidosis and their use produces symptomatic, radiographic, and functional improvement. There is, however, uncertainty regarding their effects on the overall natural history of the condition and long term benefit is unproven.

Methods - Patients with pulmonary radiographic shadowing due to sarcoidosis were recruited in a multicentre study. Those who, in the first six months after entry to the study, neither required prednisolone for symptoms nor showed radiographic improvement were allocated at six months to receive either long term steroid treatment (group L) or selective treatment (group S), with regular assessment over the subsequent five years. Patients in group $L$ were scheduled to receive steroid treatment for at least 18 months with the policy of achieving and maintaining maximal radiographic clearing, while in group $S$ treatment was reserved for use only if warranted by later development of symptoms or deteriorating lung function. Symptoms, radiographic appearances, and respiratory function were assessed
\end{abstract} periodically during the study.

Results - One hundred and forty nine patients were followed: 33 required prednisolone for troublesome symptoms within six months of entry and 58 showed radiographic improvement over this period. The remaining 58 patients were allocated to groups $L(n=27)$ and $S(n=31)$. Patients in group $L$ showed greater improvements in symptoms, respiratory function, and radiographic appearances than those in group S, although the differences were not large. After adjusting for differences at the time of allocation, the average difference in vital capacity between groups $L$ and $S$ at final assessment was $9 \%$ of the predicted value. Side effects of treatment were frequent but usually mild, necessitating withdrawal in only two individuals.

Conclusions - After excluding those individuals who required steroids for control of symptoms, approximately half of the remaining patients with sarcoidosis and pulmonary shadowing showed spontaneous radiographic improvement during six months of observation. In those in whom the radiograph failed to improve, prolonged steroid treatment with the aim of optimising radiographic appearances resulted in a significantly better long term functional outcome.

(Thorax 1996;51:238-247)

Keywords: sarcoidosis, corticosteroids, long term outcome.

The optimal treatment of patients with pulmonary sarcoidosis is not known. There is general agreement on the effect of corticosteroids in suppressing the acute consequences of widespread pulmonary granulomas, but their effects on the overall natural history and any long term benefits are much less certain. Some authorities advocate long term use in order to prevent chronic lung damage, ${ }^{12}$ while others are less convinced of benefit. ${ }^{3-5}$ Many of the previous studies performed to address this question may be criticised on the grounds that they were retrospective, uncontrolled, or included patients with only bilateral hilar lymphadenopathy where the prognosis without treatment is known to be good. Controlled studies $^{5-13}$ have generally failed to show an advantage of treatment when follow up has continued for a number of years. In most studies, however, steroids have been used in fixed treatment schedules from the time of presentation, while in clinical practice treatment is often deferred pending possible spontaneous improvement and the duration and doses of steroid are tailored to the progress of the individual.

There appeared therefore to be a need for a study of the long term effects of steroids in pulmonary sarcoidosis: (a) which concentrated on those patients whose condition was not showing rapid spontaneous resolution; (b) where the treatment could be adjusted (increased, maintained or restarted) with the aim of achieving and maintaining radiographic appearances that were as normal as possible; and (c) where comparison was made with a similar group who were untreated. This last condition implies that such a study would be possible only after excluding patients who require steroid treatment for troublesome symptoms. 
A protocol was developed, incorporating these points, to assess whether use of steroids for pulmonary sarcoidosis improved the long term outcome in terms of symptoms, radiographic appearances, and pulmonary function. The period of observation before treatment and the recommended doses and duration of treatment were based on the most frequent clinical practice, as judged by answers to a preliminary questionnaire sent to all UK consultant respiratory physicians.

\section{Methods \\ PROTOCOL}

Patients were recruited on a multicentre basis by consultant members of the British Thoracic Society (BTS). Those eligible were newly presenting patients with sarcoidosis and pulmonary shadowing who gave informed consent; they could be of either sex and were aged between 18 and 60 years. Patients presenting with bilateral hilar lymphadenopathy alone and no pulmonary shadowing were not recruited, but they became eligible later if pulmonary shadowing developed. Participating physicians were encouraged to obtain histological support for the diagnosis by taking an appropriate biopsy sample such as bronchial, lung, lymph node, liver or skin, the latter including a response to Kveim reagent. Patients with a diagnosis of sarcoidosis and characteristic radiographic pulmonary shadowing plus bilateral hilar lymphadenopathy were accepted into the study without histological support, but diffuse shadowing alone without histological evidence was not acceptable.

Patients were excluded from the study if at the time of presentation any of the following applied: (1) corticosteroids were required for non-respiratory sarcoidosis - for example, hypercalcaemia, neurological, cardiac, renal or ophthalmic involvement (steroid eye drops alone were allowed); (2) steroids were relatively contraindicated - for example, history of peptic ulcer, diabetes or hypertension; (3) concurrent asthma, chronic obstructive pulmonary disease, or treatment with an inhaled steroid; (4) treat-

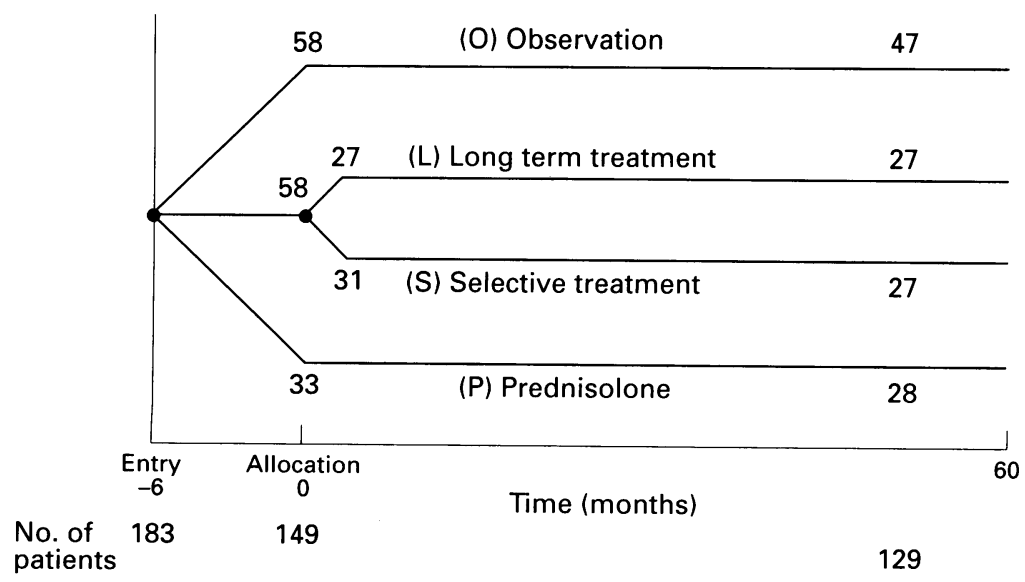

Figure 1 Outline plan of study with numbers of patients in the different groups; 58 patients were allocated six months after entry to either long term $(L)$ or selective $(S)$ treatment, a further 58 were followed by observation only $(O)$, while 33 received prednisolone within six months of entry $(P)$. Numbers on the right hand side indicate those followed for $>4$ years. ment at presentation or in the preceding two years with oral steroids for any reason; (5) cooperation was thought likely to be poor or emigration was likely.

The time of entry to the study was defined as presentation with, or recognition of, pulmonary shadowing.

According to the protocol (fig 1) stable patients were to be observed for a period of six months from entry before allocation to one of the main study groups. It was recognised that a proportion would require steroids at entry or during the subsequent six months either because of troublesome symptoms or seriously impaired or deteriorating pulmonary function (group P). Although they were not part of the main comparative study, their progress was followed with regular assessments from participating physicians over the subsequent five years. It was also anticipated that a proportion of patients would show radiographic improvement during the first six months following entry; again these were not allocated to one of the two main study groups but remained under observation (group $\mathrm{O}$ ) with regular assessment of progress. The remaining patients - that is, those who within six months of entry showed neither radiographic improvement nor required steroids were, at six months, allocated either to receive long term steroid treatment (group L) or to remain under observation with treatment given only selectively if symptoms developed or lung function deteriorated subsequently (group S). Allocation to groups $\mathrm{L}$ and $\mathrm{S}$ was determined centrally with patients allocated alternately to groups $\mathrm{L}$ and $\mathrm{S}$ throughout the period of recruitment.

\section{TREATMENT POLICIES}

"Long term" treatment (group L)

Physicians were asked to aim to produce as normal a chest radiograph as possible. The suggested treatment schedule was prednisolone $30 \mathrm{mg}$ daily for one month followed by $20 \mathrm{mg}$ daily for one month, $15 \mathrm{mg}$ daily for one month, and $10 \mathrm{mg}$ daily for nine months - that is, at least $10 \mathrm{mg}$ daily for one year. If the chest radiograph failed to improve with $30 \mathrm{mg}$ the dose was to be increased until improvement occurred or unacceptable side effects developed. If the shadowing increased as the dose was reduced to $10 \mathrm{mg}$ daily, the lowest dose which maintained maximum radiographic improvement was to be resumed and maintained for nine months before again reducing. If this still failed to produce improvement the $30 \mathrm{mg}$ dose was to be resumed and the above dosage schedule followed until the lowest effective dose was reached and maintained for nine months before reduction. After one year of treatment, provided improvement had been maintained, the dose was to be reduced to zero in stepwise fashion over six months. Physicians were advised that recurrence of shadowing during this final phase of dose reduction should lead to an increase for a further six months before another attempt at reduction was made. If steroid therapy exceeded three years the doses used were at the discretion of the physician. 
Selective treatment (group $S$ )

It was requested that treatment of these patients be reserved for specific indications based on symptoms or functional deterioration. If treatment became necessary, it was recommended that it be aimed at relieving dyspnoea and improving lung function and not at optimising radiographic appearances. The criteria suggested for instituting steroid therapy in these patients were either:

1. Symptomatic: if the patient developed distressing cough or shortness of breath which was interfering with daily activities and which the physician would normally regard as an indication for treatment.

2. Functional: any of the following (in each case confirmed by repeat measurement on a second occasion): (a) if vital capacity (VC) fell to $<75 \%$ of the best recorded value for that patient before any treatment; (b) in the absence of airway obstruction VC fell to $50 \%$ of the predicted value; or (c) if the carbon monoxide transfer factor (TLCO) fell to $<60 \%$ of the best recorded value prior to treatment.

The initial dose of prednisolone advised was $30 \mathrm{mg}$ daily for one month with gradual reduction to zero over 6-9 months subject to satisfactory progress as judged by symptomatic and functional criteria. The physician was at liberty to maintain treatment for longer or to increase the dose if progress was not satisfactory.

Prednisolone group (P)

The guidelines for treatment were similar to those for group $S$ above.

Observation group (O)

If patients showed later symptomatic or functional decline the guidelines for treatment were as for group $S$ above.

\section{STUDY DESIGN}

Follow up was performed by the physician who entered the patient in the study unless the patient moved to another district, in which case strenuous efforts were made to ensure that further follow up and assessments were performed by the local respiratory physician.

Regular assessments comprised a simple questionnaire, measurements of lung function, and a posteroanterior chest radiograph. Assessments were planned in all patients at entry, three and six months after entry, and subsequently at intervals varying between one and 12 months for a total period of five years from allocation. The precise schedule of assessments varied between groups but was similar for the comparative groups $\mathrm{L}$ and $\mathrm{S}$.

The symptomatic assessment included grading of breathlessness of increasing severity from 0 to 4 (modified from the MRC grades).

Lung function was assessed by spirometric measurements of forced expiratory volume in one second $\left(\mathrm{FEV}_{1}\right)$ and vital capacity (VC)
Table 1 Combined clinical score

\begin{tabular}{llr}
\hline & & Score \\
\hline Lung function & Increase in VC $>0 \cdot 21$ & +1 \\
& Decrease in VC $>0 \cdot 21$ & -1 \\
& Otherwise & 0 \\
Breathlessness & Improvement & +1 \\
& Deterioration & -1 \\
& Unchanged & 0 \\
Chest radiograph & Increased & -1 \\
F type shadowing & Otherwise & 0 \\
\hline VC = vital capacity & &
\end{tabular}

with, where available, carbon monoxide transfer factor (TLCO) and transfer coefficient (KCO) by the single breath technique. Values for each individual were expressed as percentages of the appropriate reference value. ${ }^{14}$

Radiographic changes were assessed in the first instance by the participating physician. All radiographs were subsequently graded by two physicians (MFM and WGM) using a system developed specifically for this study. In brief, for each radiograph the two readers agreed an assessment of shadowing of one or more of four types:

$\mathrm{R}=$ reticulonodular (small rounded and/or fine linear opacities with mean diameter $<5 \mathrm{~mm}$ )

$\mathrm{M}=$ macronodular (discrete nodules with mean diameter $>5 \mathrm{~mm}$ );

$\mathrm{C}=$ confluent (patchy homogeneous alveolar shadowing simulating consolidation);

$\mathrm{F}=$ "fibrotic" (irregular linear opacities with or without distortion of the normal vascular pattern, contraction of lung tissue, cysts or bullae). Linear opacities in the absence of the other features were accepted as type $\mathrm{F}$ shadows only if they were persistent when films were reviewed in sequence.

Shadowing was assessed in terms of extent and profusion, each on a scale from 0 to 4 . An overall score for each type of shadowing was obtained by multiplying the extent and profusion scores; scores could therefore vary between 0 and 16. The presence or absence of lymphadenopathy, pleural and cardiac abnormalities on each radiograph was also noted. Throughout, the readers assessed radiographs of groups $\mathrm{L}$ and $\mathrm{S}$ together without knowledge of the allocation of individual patients.

The main analyses were based on breathlessness scores, lung function and radiographic scores obtained in each subject at the times of allocation and final assessment.

In addition, a combined "clinical score" defined prospectively in terms of breathlessness grade, functional, and radiographic data (table 1) was calculated from differences seen between allocation and final assessment. This represents an attempt to mimic the clinical situation by combining the different forms of information used in practice to assess whether or not a patient has improved on treatment. Using the criteria specified in table 1, the "clinical score" for changes between allocation and final assessment could vary between -3 and 
Table 2 Composition of groups

\begin{tabular}{|c|c|c|c|c|}
\hline & \multicolumn{4}{|l|}{ Group } \\
\hline & $L$ & $S$ & $O$ & $P$ \\
\hline $\begin{array}{l}\text { Initial allocation } \\
\text { Incorrect allocation (chest radiography review) } \\
\text { Withdrawn (changed diagnosis)* }\end{array}$ & $\begin{array}{r}33 \\
5 \\
1\end{array}$ & $\begin{array}{r}33 \\
1 \\
1\end{array}$ & $\begin{array}{r}67 \\
9 \\
0\end{array}$ & $\begin{array}{r}35 \\
0 \\
2\end{array}$ \\
\hline $\begin{array}{l}\text { Study group } \\
\text { Defaulted }<4 \text { years } \\
\text { Followed } \geqslant 4 \text { years }\end{array}$ & $\begin{array}{r}27 \\
0 \\
27\end{array}$ & $\begin{array}{c}31 \\
4 \dagger\end{array}$ & $\begin{array}{l}58 \\
11 \\
47\end{array}$ & $\begin{array}{l}33 \\
5 \ddagger \\
28\end{array}$ \\
\hline Mean (SD) follow up period (years) & $5 \cdot 2(0.5)$ & $5 \cdot 0(1.5)$ & $4 \cdot 6(1 \cdot 8)$ & $4.9(1 \cdot 6)$ \\
\hline
\end{tabular}

$\mathrm{L}=$ long term treatment; $\mathrm{S}=$ selective treatment; $\mathrm{O}=$ observation group; $\mathrm{P}=$ prednisolone group * Cryptogenic fibrosing alveolitis (2), lymphoma (1), uncertain (1).

Including one patient who underwent lung transplantation 3 years 5 months after allocation.

$\neq$ Including one patient who died 2 years 2 months after allocation.

+2 , with a negative figure indicating an adverse outcome and 0 representing no change.

All histological material was reviewed without knowledge of the study groups by one individual (DNM) and graded as "compatible with sarcoidosis", "indeterminate", or negative.

STATISTICAL METHODS

Differences between groups were compared using analysis of variance (ANOVA) for continuous variables and $\chi^{2}$ tests for categorical variables. Analysis of covariance was used to compare the outcome in groups $\mathrm{L}$ and $\mathrm{S}$.

Table 3 Demographic data

\begin{tabular}{|c|c|c|c|c|c|}
\hline & \multicolumn{4}{|l|}{ Group } & \multirow[t]{2}{*}{$p$} \\
\hline & $L$ & $S$ & $O$ & $P$ & \\
\hline \multicolumn{6}{|l|}{ Sex } \\
\hline Male & 22 & 16 & 35 & 18 & \\
\hline Female & 5 & 15 & 23 & 15 & $0.05<p<0.1 *$ \\
\hline Mean (SD) age (years) & $40 \cdot 5(8 \cdot 8)$ & $38 \cdot 1(10 \cdot 8)$ & $33 \cdot 2(10 \cdot 6)$ & $39 \cdot 2(11 \cdot 6)$ & $<0.01 \dagger$ \\
\hline \multicolumn{6}{|l|}{ Ethnic group } \\
\hline White & 26 & 29 & 55 & 30 & \\
\hline Non-white & 1 & 2 & 3 & 3 & \\
\hline \multicolumn{6}{|l|}{ Smoking history } \\
\hline Never & 16 & 15 & 27 & 21 & \\
\hline Ex-smoker & 7 & 14 & 15 & 11 & $<0 \cdot 05^{*}$ \\
\hline Current & 4 & 2 & 16 & 1 & \\
\hline
\end{tabular}

$\mathrm{p}$ values refer to comparison between the four groups by $\chi^{2}$ test* or ANOVA†.

Table 4 Clinical and histological information at entry

\begin{tabular}{|c|c|c|c|c|c|}
\hline & \multicolumn{4}{|l|}{ Group } & \multirow[t]{2}{*}{$p$} \\
\hline & $\begin{array}{l}L \\
(n=27)\end{array}$ & $\begin{array}{l}S \\
(n=31)\end{array}$ & $\begin{array}{l}O \\
(n=58)\end{array}$ & $\begin{array}{l}P \\
(n=33)\end{array}$ & \\
\hline \multicolumn{6}{|l|}{ Clinical } \\
\hline \multicolumn{6}{|l|}{ Main presenting feature: } \\
\hline Radiography only & 7 & 4 & 12 & 1 & \\
\hline Respiratory symptoms & 17 & 18 & 18 & 24 & $<0.001$ \\
\hline Erythema nodosum & 1 & 0 & 18 & 0 & \\
\hline \multirow{2}{*}{\multicolumn{6}{|c|}{ Recent erythema nodosum: }} \\
\hline & & & & & $<0.001$ \\
\hline Present & 1 & 1 & 20 & 5 & \\
\hline \multicolumn{6}{|c|}{ Histological (Kveim or other biopsy) } \\
\hline $\begin{array}{l}\text { Biopsy compatible with } \\
\text { sarcoidosis }\end{array}$ & 20 & 27 & 40 & 31 & \\
\hline $\begin{array}{l}\text { Biopsy negative/ } \\
\text { indeterminate }\end{array}$ & 7 & 4 & 10 & 1 & \\
\hline No biopsy performed & 0 & 0 & 8 & 1 & \\
\hline
\end{tabular}

$\mathrm{p}$ values refer to comparison between four groups $\left(\chi^{2}\right.$ text).

\section{Results}

One hundred and eighty three patients were recruited to the study by 70 physicians over the period 1981-6. Of these, 15 were excluded before allocation because of unwillingness to continue $(n=3)$, use of steroids for other indications $(n=3)$, absence of pulmonary shadowing at entry $(n=2)$, and failure to attend for the first follow up appointment $(n=7)$.

Of the remaining 168 patients, 35 were considered to require treatment with prednisolone at or within six months of entry (group P). In 66 patients the physician reported no radiographic improvement after six months and these were allocated to groups L or S. In 67 patients the physician reported improvement at six months and these were therefore allocated to group $O$. When the radiographs were assessed subsequently it was apparent that 15 patients had been allocated inappropriately to groups $L, S$, or $\mathrm{O}$. In addition, four patients were withdrawn later because of a change of diagnosis, leaving 149 who represent the subject of this report (table 2, fig 1). Inevitably there were some further defaulters during the follow up period, particularly among patients whose condition had improved and who were not receiving regular treatment, but 129 patients were followed for at least four years (table 2).

For the final analysis, data on all patients in each study group as defined in table 2 have been included using five year follow up results where available or the latest information obtained in those who had defaulted before five years. In some individuals in whom information at five years had not been obtained because of earlier defaulting, final assessments were subsequently obtained more than five years after allocation following repeated enquiries and requests to the physicians and patients concerned. For these reasons, the average follow up in all groups was close to five years (table 2).

DEMOGRAPHIC DATA (table 3)

The subjects recruited to the study showed a male preponderance in a ratio of $1 \cdot 6: 1$ and only nine of the 149 were non-white. Patients in group $\mathrm{O}$ were notably younger on average than other patients in the study. Overall, 53\% of subjects had never smoked and only $15 \%$ were current smokers with the highest proportion of current smokers in group $\mathrm{O}$.

\section{FEATURES AT ENTRY AND ALLOCATION}

Clinical, radiographic, functional, and histological data at entry and allocation are summarised in tables 4 and 5 . Histological support for the diagnosis was obtained in $79 \%$ of the patients. No supportive histological information was available in 31 patients, all of whom had characteristic radiographic features of bilateral hilar lymphadenopathy plus pulmonary shadowing.

Respiratory symptoms were the main presenting feature in most of the patients in groups $\mathrm{L}, \mathrm{S}$, and $\mathrm{P}$, while in group $\mathrm{O}$ erythema nodosum was an equally common main feature. 
Table 5 Data at allocation

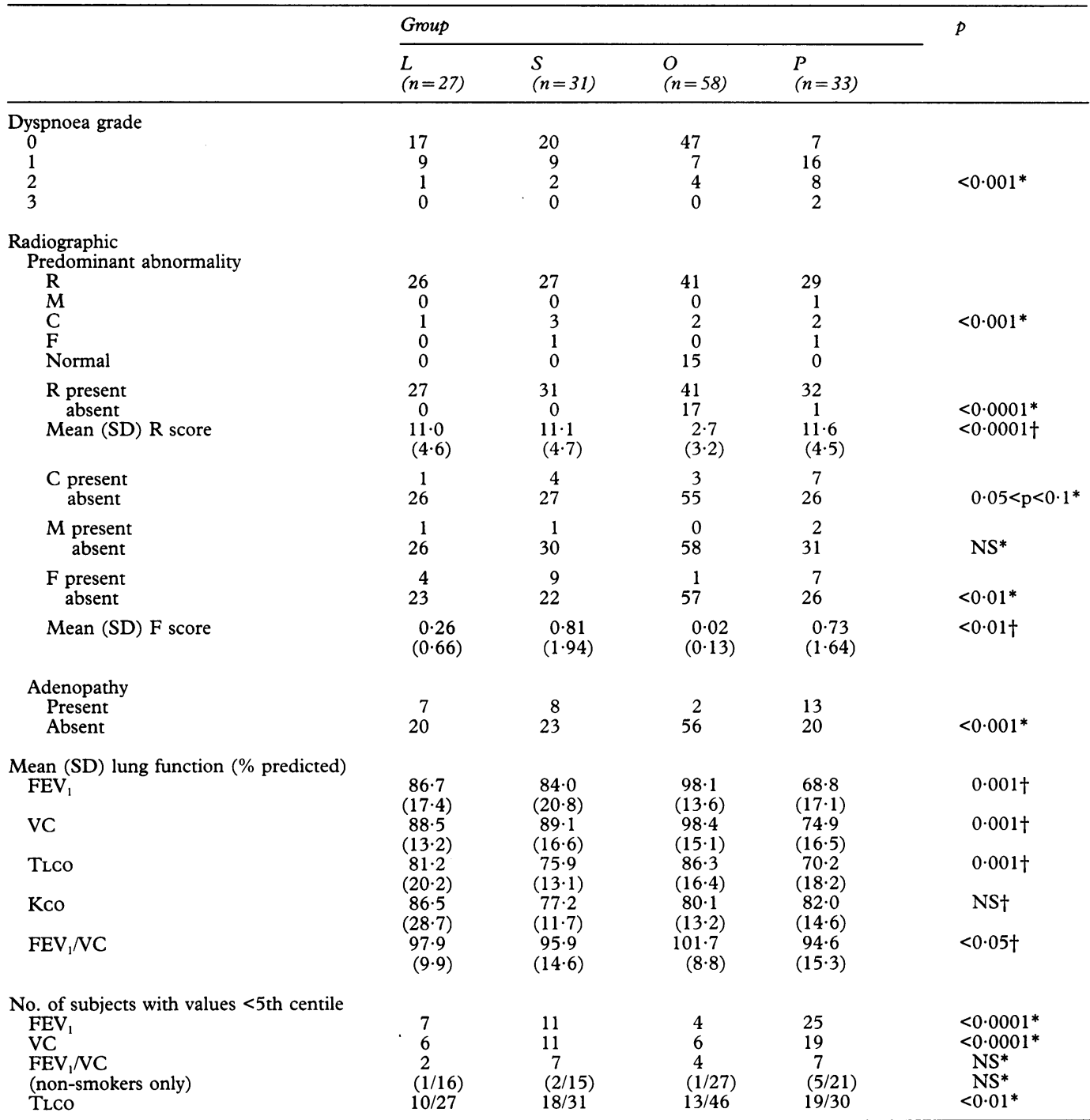

$\mathrm{p}$ values refer to comparison between the four groups by $\chi^{2}$ test* or ANOVAt.

$\mathrm{R}=$ reticulonodular; $\mathrm{M}=$ macronodular; $\mathrm{C}=$ confluent; $\mathrm{F}=$ "fibrotic"; $\mathrm{FEV} \mathrm{V}_{1}=$ forced expiratory volume in one second; $\mathrm{VC}=$ vital capacity; $\mathrm{T} L \mathrm{CO}=$ carbon monoxide transfer factor; $\mathrm{KCO}=$ transfer coefficient.

As expected, patients in group $\mathbf{P}$ had more severe dyspnoea than those in the other groups; the severity was similar in the main comparative groups $\mathrm{L}$ and $\mathrm{S}$.

In all groups the predominant pulmonary shadowing was type $R$. Shadowing of types C and $M$ was uncommon, but it was noteworthy that type $F$ shadows, suggestive of fibrosis, were recognised at allocation in 21 radiographs. Hilar and/or mediastinal lymphadenopathy was present in 30 of the 149 radiographs at allocation. Although only two patients in group O showed adenopathy at allocation, it should

Table 6 Steroid treatment

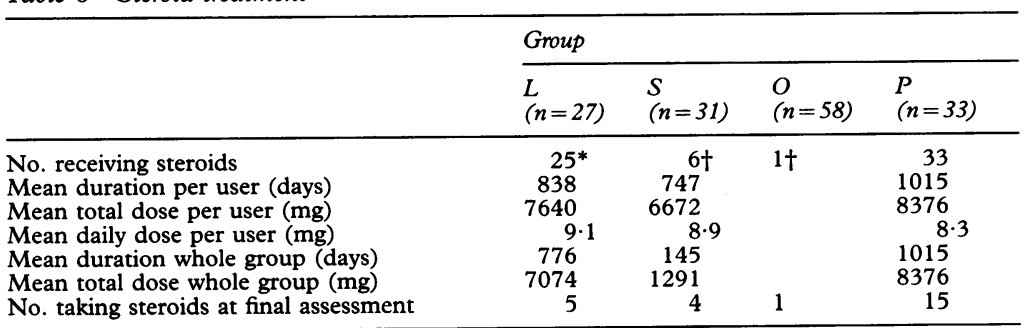

* Two patients received no steroid (see text).

t Six respiratory symptoms \pm deteriorating function, one lupus pernio. be borne in mind that these radiographs were obtained six months after entry; the corresponding radiographs at entry showed 31 from group $\mathrm{O}$ with adenopathy. The 15 patients in group $\mathrm{O}$ with normal radiographic appearances had shown complete resolution of pulmonary shadowing in the preceding six months and clearing was partial in the other 43 patients.

Lung function at allocation (table 5) showed similar mild reductions in spirometric volumes in groups $\mathrm{L}$ and $\mathrm{S}$ with more marked reduction in patients in group $\mathrm{P}$ and values close to normal in those in group O. In general, TLCo was reduced proportionately a little more than the spirometric volumes. The average $\mathrm{FEV}_{1} /$ VC ratio was close to normal in all groups. Also shown are the number of values in each group which were below the fifth centile - that is, more than $1.65 \mathrm{SD}$ below the mean reference value. Overall, the most frequent abnormality, according to this definition, was a reduction in TLCo. Airway obstruction, as defined by $\mathrm{FEV}_{1} /$ VC below the fifth centile, was present at allocation in 20 subjects, nine of whom were non-smokers. 
Table 7 Side effects of treatment

\begin{tabular}{llll}
\hline & $\begin{array}{c}\text { Group } L \\
(n=27)\end{array}$ & $\begin{array}{l}\text { Group } S \\
(n=31)\end{array}$ & $p^{*}$ \\
\hline Weight gain within 12 months (kg) & $\begin{array}{c}+3 \cdot 26 \\
(3 \cdot 76)\end{array}$ & $\begin{array}{c}+0 \cdot 99 \\
(3 \cdot 21)\end{array}$ & $0 \cdot 02$ \\
Weight gain between allocation and final assessment $(\mathrm{kg})$ & $\begin{array}{c}+3 \cdot 54 \\
(5 \cdot 24)\end{array}$ & $\begin{array}{c}+2 \cdot 79 \\
(5 \cdot 21)\end{array}$ & $\mathrm{NS}$ \\
& $\mathrm{n}=25$ & $\mathrm{n}=6$ & \\
Reported side effects & 12 & 2 & \\
Weight gain/cushingoid features & 5 & 0 & \\
Gastrointestinal disturbance & 2 & 0 & \\
Acne & 1 & 0 & \\
Hypertension & 1 & 0 & \\
Insomnia & 1 & 0 & \\
Cramps & 1 & 0 & \\
Visual blurring & 17 & 2 & \\
Total reporting side effects & 2 & 0 & \\
No. necessitating cessation or interruption of treatment & 2 & & \\
\hline
\end{tabular}

* Two sample $t$ test.
$S$, six later received steroids, five because of the development of troublesome respiratory symptoms and/or deteriorating function and one for treatment of lupus pernio. Similarly, one of the 58 patients in group $O$ later received steroids because of respiratory symptoms. By definition, all patients in group $P$ received prednisolone. For the groups as a whole there was an almost sixfold difference between the total dose of steroids received by patients in groups $\mathrm{L}$ and $\mathrm{S}$. Of the 65 patients receiving steroids, 25 were still taking them at the time of final assessment including five in group $\mathrm{L}$ in whom initiation of steroid treatment was determined by the study protocol rather than by respiratory symptoms or function. Several side effects of steroid treatment were noted (table 7). As expected, patients in group $\mathrm{L}$ showed a greater increase in weight during the first 12 months of the study but by the end of the study the difference between groups $\mathrm{L}$ and $\mathrm{S}$ was no longer significant.

Details of steroid treatment are shown in table 6 . Two of the patients allocated to group L did not receive steroids, in one case because the patient declined and in the second because a repeat chest radiograph performed by the participating physician just before planned initiation of treatment showed definite evidence of clearing. Of the patients allocated to group

DATA AT FINAL ASSESSMENT

Table 8 shows clinical, radiographic, and functional data at the time of the final assessment

Table 8 Data at final assessment

\begin{tabular}{|c|c|c|c|c|c|}
\hline & \multicolumn{4}{|l|}{ Group } & \multirow[t]{2}{*}{$p$} \\
\hline & $\begin{array}{l}L \\
(n=27)\end{array}$ & $\begin{array}{l}S \\
(n=31)\end{array}$ & $\begin{array}{l}O \\
(n=58)\end{array}$ & $\begin{array}{l}P \\
(n=33)\end{array}$ & \\
\hline $\begin{array}{l}\text { Dyspnoea grade: } \\
0 \\
1 \\
2 \\
3\end{array}$ & $\begin{array}{r}23 \\
3 \\
1 \\
0\end{array}$ & $\begin{array}{r}19 \\
9 \\
2 \\
1\end{array}$ & $\begin{array}{r}52 \\
6 \\
0 \\
0\end{array}$ & $\begin{array}{r}16 \\
15 \\
2 \\
0\end{array}$ & $0.001^{*}$ \\
\hline $\begin{array}{l}\text { Radiographic } \\
\text { Predominant abnormality } \\
\text { R } \\
M \\
\text { C } \\
\text { F } \\
\text { Normal }\end{array}$ & $\begin{array}{r}18 \\
0 \\
0 \\
2 \\
7\end{array}$ & $\begin{array}{r}15 \\
0 \\
1 \\
7 \\
8\end{array}$ & $\begin{array}{r}16 \\
0 \\
0 \\
1 \\
41\end{array}$ & $\begin{array}{r}19 \\
1 \\
2 \\
5 \\
6\end{array}$ & $<0.001^{*}$ \\
\hline $\begin{array}{c}\mathrm{R} \text { present } \\
\text { absent }\end{array}$ & $\begin{array}{r}19 \\
8\end{array}$ & $\begin{array}{l}21 \\
10\end{array}$ & $\begin{array}{l}17 \\
41\end{array}$ & $\begin{array}{r}24 \\
9\end{array}$ & $<0.0001^{*}$ \\
\hline Mean (SD) $R$ score & $\begin{array}{c}4 \cdot 56 \\
(4 \cdot 62)\end{array}$ & $\begin{array}{c}4 \cdot 68 \\
(5 \cdot 54)\end{array}$ & $\begin{array}{c}1 \cdot 19 \\
(2 \cdot 53)\end{array}$ & $\begin{array}{c}5 \cdot 70 \\
(5 \cdot 08)\end{array}$ & $<0.0001 \dagger$ \\
\hline $\begin{array}{c}\mathrm{C} \text { present } \\
\text { absent }\end{array}$ & $\begin{array}{r}2 \\
25\end{array}$ & $\begin{array}{r}1 \\
30\end{array}$ & $\begin{array}{r}0 \\
58\end{array}$ & 31 & NS* \\
\hline $\begin{array}{c}M \text { present } \\
\text { absent }\end{array}$ & $\begin{array}{r}0 \\
27\end{array}$ & $\begin{array}{r}0 \\
31\end{array}$ & $\begin{array}{r}0 \\
58\end{array}$ & $\begin{array}{r}2 \\
31\end{array}$ & $0.05<\mathrm{p}<0.1^{*}$ \\
\hline $\begin{array}{c}\text { F present } \\
\text { absent }\end{array}$ & $\begin{array}{r}7 \\
20\end{array}$ & $\begin{array}{l}13 \\
18\end{array}$ & $\begin{array}{r}1 \\
57\end{array}$ & $\begin{array}{l}11 \\
22\end{array}$ & $<0.001^{*}$ \\
\hline Mean (SD) F score & $\begin{array}{c}0.44 \\
(0 \cdot 85)\end{array}$ & $\begin{array}{c}1 \cdot 81 \\
(3 \cdot 42)\end{array}$ & $\begin{array}{c}0.07 \\
(0.52)\end{array}$ & $\begin{array}{c}1 \cdot 21 \\
(2 \cdot 31)\end{array}$ & $0.001 \dagger$ \\
\hline $\begin{array}{l}\text { Adenopathy } \\
\text { Present } \\
\text { Absent }\end{array}$ & $\begin{array}{r}6 \\
21\end{array}$ & $\begin{array}{r}4 \\
27\end{array}$ & $\begin{array}{r}0 \\
58\end{array}$ & $\begin{array}{r}2 \\
31\end{array}$ & $<0.005^{*}$ \\
\hline $\begin{array}{l}\text { Mean (SD) lung function (\% predicted) } \\
\text { FEV }_{1} \\
\text { VC } \\
\text { TLCo } \\
\text { KCo } \\
\text { FEV }_{1} / \text { VC }\end{array}$ & $\begin{array}{l}96 \cdot 3 \\
(19 \cdot 9) \\
98 \cdot 9 \\
(14 \cdot 6) \\
86 \cdot 4 \\
(16 \cdot 4) \\
83 \cdot 0 \\
(23 \cdot 0) \\
98 \cdot 0 \\
(11 \cdot 7)\end{array}$ & $\begin{array}{l}86 \cdot 5 \\
(23 \cdot 3) \\
91 \cdot 7 \\
(21 \cdot 1) \\
75 \cdot 6 \\
(14 \cdot 4) \\
74 \cdot 4 \\
(14 \cdot 7) \\
96 \cdot 9 \\
(16 \cdot 3)\end{array}$ & $\begin{array}{l}98 \cdot 3 \\
(14 \cdot 0) \\
99 \cdot 9 \\
(14 \cdot 5) \\
92 \cdot 7 \\
(17 \cdot 7) \\
80 \cdot 4 \\
(13 \cdot 4) \\
100 \cdot 9 \\
(10 \cdot 1)\end{array}$ & $\begin{array}{l}78 \cdot 5 \\
(19 \cdot 7) \\
89 \cdot 3 \\
(26 \cdot 4) \\
76 \cdot 1 \\
(21 \cdot 9) \\
75 \cdot 0 \\
(16 \cdot 5) \\
92 \cdot 3 \\
(17 \cdot 9)\end{array}$ & $\begin{array}{l}<0.001 \dagger \\
<0.05 t \\
<0.001 \dagger \\
\mathrm{NSt} \\
0.05 \dagger\end{array}$ \\
\hline $\begin{array}{l}\text { No. of subjects with values }<5 \text { th centile } \\
\text { FEV } \\
\text { VC } \\
\text { FEV } 1 \text { VC } \\
\text { TLCO }\end{array}$ & $\begin{array}{l}4 \\
1 \\
5 \\
8 / 25\end{array}$ & $\begin{array}{c}10 \\
8 \\
8 \\
14 / 27\end{array}$ & $\begin{array}{l}5 \\
6 \\
6 \\
9 / 46\end{array}$ & $\begin{array}{l}13 \\
10 \\
9 \\
17 / 30\end{array}$ & $\begin{array}{l}<0.005^{*} \\
<0.05^{*} \\
\text { NS* }^{*} \\
<0.005^{*}\end{array}$ \\
\hline
\end{tabular}

$\mathrm{R}=$ reticulonodular; $\mathrm{M}=$ macronodular; $\mathrm{C}=$ confluent; $\mathrm{F}=$ "fibrotic".

$\mathrm{p}$ values refer to comparison between the four groups by $\chi^{2}$ test $^{*}$ or ANOVA + . 
Table 9 Mean (SD) changes between allocation and final assessment in groups $L$ and $S$

\begin{tabular}{|c|c|c|c|}
\hline & Group $I$ & Group $S$ & $p^{*}$ \\
\hline $\begin{array}{l}\text { Symptoms: } \\
\Delta \text { Dyspnoea grade }\end{array}$ & $0 \cdot 22(0 \cdot 58)$ & $+0.10(0.65)$ & $0.05<\mathrm{p}<0.1$ \\
\hline $\begin{array}{l}\text { Radiography: } \\
\Delta \mathrm{R} \text { score } \\
\mathrm{F} \text { developed } \\
\Lambda \mathrm{F} \text { score }\end{array}$ & $\begin{array}{c}6 \cdot 48(7 \cdot 2) \\
3 \\
+0 \cdot 2(0 \cdot 6)\end{array}$ & $\begin{array}{l}6.39(6.8) \\
4 \\
+1.0(2 \cdot 2)\end{array}$ & $\begin{array}{l}\text { NS } \\
0 \cdot 0 \overline{5}<\mathrm{p}<0 \cdot 1\end{array}$ \\
\hline $\begin{array}{l}\text { Lung function (\% predicted): } \\
\triangle \mathrm{FEV}_{1} \\
\Delta \mathrm{VC} \\
\Delta \mathrm{TLCO} \\
\Delta \mathrm{KCO} \\
\Delta \mathrm{FEV}_{1} / \mathrm{VC}\end{array}$ & $\begin{array}{l}+9 \cdot 5(16 \cdot()) \\
-10 \cdot 4(14 \cdot 4) \\
+5 \cdot 9(19 \cdot 1) \\
-0 \cdot 5(13 \cdot 1) \\
+0 \cdot 1(11 \cdot 2)\end{array}$ & $\begin{array}{r}+2.5(13.1) \\
+2.6(13.2) \\
-1.0(14 \cdot 1) \\
0.9(7.4) \\
-1.0(12.3)\end{array}$ & $\begin{array}{l}0 \cdot 05<\mathrm{p}<0 \cdot 1 \\
<0 \cdot 05 \\
\text { NS } \\
\text { NS } \\
\text { NS }\end{array}$ \\
\hline
\end{tabular}

$\mathrm{FEV}_{1}=$ forced expiratory volume in one second; $\mathrm{VC}=$ vital capacity; Tl.co = carbon monoxide transfer factor; $\mathrm{KCO}=$ transfer coefficient.

transfer factor; KCO
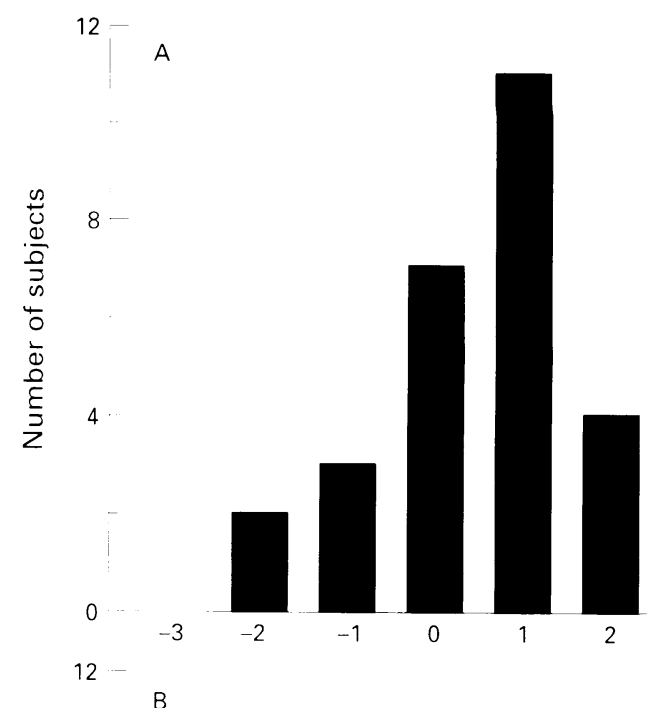

at allocation (table 5). The dyspnoea grade remained higher in patients in group $\mathrm{P}$ than in the other groups, and dyspnoea was reported by 12 of 31 patients in group S compared with four of 27 in group L. The predominant pulmonary shadowing remained reticulonodular $(\mathrm{R})$ in most instances; 41 of the 58 patients in group $\mathrm{O}$ had regained normal radiographic appearances compared with seven and eight in groups $\mathrm{L}$ and $\mathrm{S}$, respectively.

The total number of patients showing "fibrotic" $(\mathrm{F})$ shadows had increased from 21 to 32 . Adenopathy was still recognised in 12 radiographs. Most indices of pulmonary function had, on average, increased apart from Kco which was little changed. Small increases were seen in all groups in the numbers of patients with a reduced $\mathrm{FEV}_{1} / \mathrm{VC}$ ratio.

COMPARISON OF GROUPS L AND S

The changes between allocation and final assessment in dyspnoea grade, radiographic scores, and lung function are shown in table 9. There was a consistent trend for patients in group $S$ to fare less well in terms of symptoms, radiographic evidence of fibrosis, and respiratory function; on average they failed to show the small improvements seen in group L. Since there were some differences between groups $\mathrm{L}$ and $\mathrm{S}$ at allocation, in particular

Table 10 Comparison of success of treatment in groups $L$ and $S$

\begin{tabular}{|c|c|c|c|}
\hline & Group $L$ & Group $S$ & $p^{*}$ \\
\hline $\begin{array}{l}\text { Symptoms: } \\
\text { Grade of dyspnoea }\end{array}$ & $\begin{array}{c}0.24 \\
(0.11)\end{array}$ & $\begin{array}{l}0.47 \\
(0.10)\end{array}$ & is \\
\hline $\begin{array}{l}\text { Radiographic: } \\
\text { Score of F }\end{array}$ & $\begin{array}{c}0.83 \\
(0.32)\end{array}$ & $\begin{array}{c}1.47 \\
(0.29)\end{array}$ & NS \\
\hline $\begin{array}{l}\text { Lung function (\% predicted): } \\
\text { FEV }_{1} \\
\text { VC } \\
\text { TI.CO } \\
\text { KCO } \\
\text { FEV }_{1} \text { VC }\end{array}$ & $\begin{array}{l}95 \cdot 9 \\
(2 \cdot 9) \\
99 \cdot 8 \\
(2 \cdot 7) \\
84 \cdot 3 \\
(2 \cdot 9) \\
80 \cdot 4 \\
(2 \cdot 4) \\
96 \cdot 5 \\
(2 \cdot 3)\end{array}$ & $\begin{array}{l}86 \cdot 9 \\
(2 \cdot 7) \\
90 \cdot 8 \\
(2 \cdot 5) \\
77 \cdot 7 \\
(2 \cdot 7) \\
79 \cdot 5 \\
(2 \cdot 1) \\
96 \cdot 5 \\
(2 \cdot 1)\end{array}$ & $\begin{array}{c}<0.05 \\
0.02 \\
\mathrm{NS} \\
\mathrm{NS} \\
\mathrm{NS}\end{array}$ \\
\hline
\end{tabular}

Values are mean (SE) adjusted after allowing for sex, symptoms, radiographic F, and lung function at allocation.

$\mathrm{FEV}_{1}=$ forced expiratory volume in one second; $\mathrm{VC}=$ vital capacity; TICO = carbon monoxide transfer factor; KCO = transfer coefficient.

* Analysis of covariance.

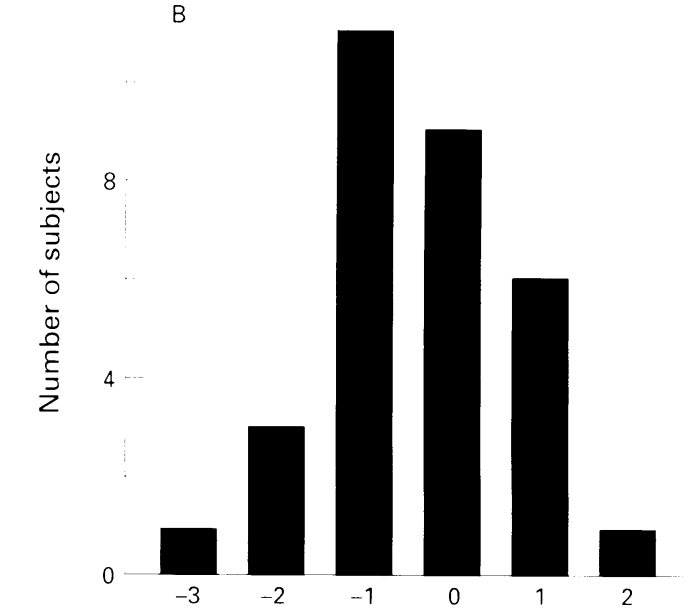

Figure 2 Changes in combined clinical scores of patients in $(A)$ group $L$ and $(B)$ group $S$ between allocition and final assessment. Positive values indicate improvement. Differences between the tao groups were significant $(p=$ $0 \cdot 01, y^{2}$ test $)$.

in sex distribution and the frequency of $\mathrm{F}$ radiographic shadows, the comparison was repeated by analysis of covariance, allowing for factors at allocation which might have influenced the outcome. The adjusted mean values for dyspnoea grade, F score, and respiratory function are shown in table 10 . The same general trends remain although only the spirometric volumes show differences which reach conventional levels of statistical significance. The average difference in spirometric volumes between the two groups after adjustment for possible confounding factors was $9 \%$ of predicted values.

The distribution of values of the combined clinical score was significantly different with an overall better outcome in patients in group $\mathrm{L}$ compared with those in group S (fig 2).

\section{Discussion}

PREVIOUS STUDIES

The short term effects of corticosteroids in pulmonary sarcoidosis are well established. ${ }^{17}$ Although several previous reports have evaluated long term benefit (table 11), this has not been shown convincingly in a controlled study. Such studies are inevitably complicated by the natural history of the condition, which in most 
Table 11 Results of previous long term studies of corticosteroids in pulmonary sarcoidosis

\begin{tabular}{|c|c|c|c|c|c|c|c|c|}
\hline Authors & $n$ & $\begin{array}{l}\text { Ethnic } \\
\text { origin }\end{array}$ & $\begin{array}{l}\text { Initial chest } \\
\text { radiographic stage* } \\
\text { (no. with lung } \\
\text { shadowing) }\end{array}$ & $\begin{array}{l}\text { Control } \\
\text { group }\end{array}$ & $\begin{array}{l}\text { Steroid treatment } \\
(\text { mg/day } \times \text { months }) \ddagger\end{array}$ & $\begin{array}{l}\text { Follow up } \\
\text { (years) }\end{array}$ & Assessment & Conclusions \\
\hline Young et $a l^{6}$ & 25 & $14 \mathrm{~B}, 11 \mathrm{~W}$ & I,II,III (?) & Alternate & $60 \times 1$ then $20 \times \geqslant 5$ & $1-2$ & Functional & No differences \\
\hline $\begin{array}{l}\text { Harkleroad } \dagger \\
\text { et } \mathrm{al}^{7}\end{array}$ & 17 & $10 \mathrm{~B}, 7 \mathrm{~W}$ & I,II,III (10) & Alternate & $60 \times 1$ then $20 \times \geqslant 5$ & $10-15$ & $\begin{array}{l}\text { Radiography, } \\
\text { functional }\end{array}$ & No differences \\
\hline $\begin{array}{l}\text { Hapke and } \\
\text { Meek }^{8}\end{array}$ & 22 & (W) & I,II,III (c. 14) & Alternate & $15 \times 6$ & 4 & $\begin{array}{l}\text { Radiography, } \\
\text { functional }\end{array}$ & No differences \\
\hline Israel et at & 83 & $75 \mathrm{~B}, 8 \mathrm{~W}$ & I,II,III (46) & $\begin{array}{l}\text { Random, } \\
\text { placebo }\end{array}$ & $15 \times 3$ & $\stackrel{1-11}{(\text { mean } 5 \cdot 2)}$ & $\begin{array}{l}\text { Clinical, } \\
\text { radiography, } \\
\text { functional }\end{array}$ & No differences \\
\hline Johns et $a l^{16}$ & 152 & 139B, 13W & II,III (152) & $\mathrm{Nil}$ & $40 \rightarrow 0 \times 9$ & $1 \rightarrow 10$ & $\begin{array}{l}\text { Clinical, } \\
\text { functional }\end{array}$ & $\begin{array}{l}\text { Improvement in } \\
>70 \%\end{array}$ \\
\hline Mikami et $a l^{9}$ & 101 & $\mathrm{~J}$ & 0,I,II,III (c.35) & $\begin{array}{l}\text { Random, } \\
\text { placebo }\end{array}$ & $\begin{array}{l}30 \times 120 \times 1 \\
10 \times 15 \times 3\end{array}$ & 1 & Radiography & No differences \\
\hline $\begin{array}{l}\text { Selroos and } \\
\text { Sellergren }^{10}\end{array}$ & 39 & $(\mathrm{~W})$ & II (39) & Random & $40 \rightarrow 0 \times 7$ & 4 & $\begin{array}{l}\text { Radiography, } \\
\text { functional }\end{array}$ & No differences \\
\hline $\begin{array}{l}\text { Yamamoto } \\
\text { et al }\end{array}$ & 74 & $\mathrm{~J}$ & $\mathrm{I}, \mathrm{II}(42)$ & $\begin{array}{l}\text { Matched } \\
\text { pairs }\end{array}$ & $30 \rightarrow 0 \times 18$ & 3 & Radiography & No differences \\
\hline Eule $e t a l^{12}$ & 172 & $(W)$ & I,II,III (105) & $\begin{array}{l}\text { Random, } \\
\text { untreated }\end{array}$ & $\begin{array}{l}40 \rightarrow 10 \times 12 \text { or } \\
40 \rightarrow 10 \times 6\end{array}$ & $\stackrel{5-14}{(\text { mean } 8.9)}$ & $\begin{array}{l}\text { Radiography, } \\
\text { functional }\end{array}$ & $\begin{array}{l}\text { No differences, } \\
\text { normal chest } \\
\text { radiography in } \\
\sim 80 \% \text { overall }\end{array}$ \\
\hline Zaki et al ${ }^{13}$ & 159 & $155 \mathrm{~B}, 4 \mathrm{~W}$ & 0,I,II,III (78) & $\begin{array}{l}\text { Random, } \\
\text { placebo }\end{array}$ & $\begin{array}{l}40 \times 3 \\
20 \times \geqslant 24\end{array}$ & $\begin{array}{l}\geqslant 3 \text { in } 70 \% \\
\geqslant 4 \text { in } 35 \%\end{array}$ & $\begin{array}{l}\text { Radiography, } \\
\text { functional }\end{array}$ & No differences \\
\hline
\end{tabular}

$\mathrm{B}=$ black; $\mathrm{W}=$ white $(\mathrm{W})=$ presumed white $\mathrm{J}=$ Japanese.

* $0=$ normal; $\mathrm{I}=$ bilateral hilar lymphadenopathy $(\mathrm{BHL})$ alone; $\mathrm{II}=\mathrm{BHL}+$ pulmonary shadowing; $\mathrm{III}=$ pulmonary shadowing alone

$* 0=$ normal; $\mathrm{I}=$ bilateral hilar lymphadenopathy (BHL) alone
+ Prolonged follow up of subgroup of patients in reference 6.

$\ddagger$ Subsequent treatment as required on clinical grounds.

individuals is towards resolution, and by the need of many patients for steroids at or shortly after presentation because of symptoms or severely impaired pulmonary function. In most patients pulmonary sarcoidosis follows a benign course with estimated rates of significant disability due to pulmonary fibrosis varying from $3 \%$ to $20 \%$ of cases. $^{2}$

Earlier studies (table 11) can be criticised on various grounds. Many included patients with bilateral hilar lymphadenopathy only and no evidence of radiographic pulmonary shadowing, a type of presentation which is known to carry a good prognosis without treatment. Previous studies used steroids from the time of presentation without allowing an initial period of observation during which many patients will show partial or complete resolution. North American studies have mainly included individuals of black ethnic group and it is generally acknowledged that the prognosis is worse in this group than in white Caucasians. It is therefore possible that the results may not be relevant to a European population. In the largest published series from Europe Eule $e t$ al ${ }^{12}$ showed no significant advantage of treatment after a mean follow up of 8.9 years. However, most of their patients were identified by mass radiography and may well have had a good prognosis even without treatment, a suggestion supported by their finding that the chest radiograph returned to normal in approximately $80 \%$ of the patients which is appreciably more than that found in other series.

CRITICISMS OF THE PRESENT STUDY

The study was designed on a multicentre basis because no one centre is likely to see sufficient patients of the type studied here to mount a large study. Since, however, our patients were under investigation and treatment by physicians in several hospitals, we were able to gather only relatively simple information regarding symptoms and lung function. More- over, we had no control over the quality of the radiographs or measurements of lung function in the different centres; in most cases, however, patients were followed up in a single centre throughout the study. Although the study was controlled it was not truly randomised as suitable patients were allocated alternately to groups $\mathrm{L}$ and $\mathrm{S}$. Since the allocation was performed centrally, however, participating physicians could not be aware of the allocation in advance and it seems unlikely that this could have influenced the results.

We chose not to include a placebo treated group as it was considered unrealistic to maintain placebo treatment for the duration of the study. As in other studies, it was not practicable to include in the two main comparative groups those patients who initially were most seriously affected (group P). In principle, the more severely affected individuals (group $P$ ) might have the greatest capacity for improvement and consequently the need to restrict the main comparative study to those with stable and generally less severe pulmonary disease may result in underestimation of the longer term benefit of steroid treatment.

Unfortunately, by chance the two main study groups $\mathrm{L}$ and $\mathrm{S}$ showed some imbalance at allocation in terms of sex distribution and the presence of recognisable $F$ type shadows on the chest radiograph. We allowed for this by repeating the comparison after adjustment for variables at the time of allocation which it was considered might have influenced the results.

Support for the diagnosis from biopsy samples was obtained in $79 \%$ of the patients. Entry to the study was based essentially on clinical criteria and for this reason four patients had to be excluded from analysis because the diagnosis was later revised. In all other instances, however, there was no reason to question the diagnosis of sarcoidosis in those in whom biopsy samples had been non-diagnostic or were not obtained. 
Despite strenuous efforts (including, in one instance, obtaining information from New Zealand on a subject who had emigrated), complete follow up could not be obtained in all patients. In the two main study groups, however, information was available for at least four years of follow up in all but four subjects.

We do not claim that the population studied here is necessarily representative of the total population of patients with sarcoidosis and pulmonary shadowing. In particular, physicians may have been deterred from entering patients with more severe disease at presentation; if such patients are relatively underrepresented, however, the proportion of patients with pulmonary sarcoidosis in whom a decision about steroid treatment is necessary after a period of observation is even less than the $40 \%$ found in the present study.

NATURAL HISTORY OF PULMONARY SARCOIDOSIS Half of the patients who did not require steroids within six months of entry showed radiographic improvement over this period. This emphasises the tendency to spontaneous resolution and the need to adopt a period of observation before initiating treatment in those who do not require urgent intervention for symptomatic reasons. Patients in this group (group O) were notably younger than those in the other groups; they also more frequently had hilar lymphadenopathy at entry and a recent history of erythema nodosum, supporting previous studies and common clinical experience that such patients have a particularly good prognosis. The rate of regression of the hilar adenopathy in this group was also notably rapid, with only two still showing recognisable bilateral hilar lymphadenopathy six months after entry. Another feature of interest in group $\mathrm{O}$ was the trend towards a higher rate of continued smoking (table 3 ). A previous study ${ }^{17}$ suggested that sarcoidosis is commoner in non-smokers than in smokers. Our results suggest additionally that continued smoking may be associated with early radiographic improvement. Only one patient in group $\mathrm{O}$ required later treatment with corticosteroids for symptomatic reasons, which also accords with clinical experience that recurrence following rapid resolution of pulmonary shadowing is distinctly unusual.

As would be expected, patients in group $P$ had generally worse symptoms and more impaired pulmonary function at the time of allocation than those in the other groups. They often continued to have troublesome symptoms and approximately half were still taking steroids at the end of the study. In many the treatment had needed to be reinstituted or the dose increased after unsuccessful attempts at withdrawal.

The frequency of functional evidence of airway obstruction in patients with sarcoidosis has been a matter of some controversy. It is widely recognised that, in patients with advanced destructive fibrotic disease, airway obstruction is common but the more typical ventilatory defect in the earlier stages of sarcoidosis has generally been regarded as re- strictive. One recent study ${ }^{18}$ suggested that, even at presentation, an obstructive ventilatory defect may be the commonest single functional abnormality. This was not, however, the case in the present study which showed a reduced TLCO to be the most frequent abnormality (table 5). Considering only lifelong nonsmokers, nine of 79 patients had an $\mathrm{FEV}_{1} / \mathrm{VC}$ below the fifth centile at the time of allocation. The frequency of airway obstruction increased during the study and was slightly higher in all groups at the final assessment compared with that at allocation (tables 5 and 8). There was a correlation between $\mathrm{FEV}_{1} / \mathrm{VC}$ ratio and $\mathrm{F}$ type shadows (unpublished data), suggesting that the increasing prevalence of airway obstruction was largely related to distortion associated with increasing fibrosis, a conclusion which accords with clinical experience in chronic sarcoidosis.

\section{EFFECT OF CORTICOSTEROIDS}

The main aim of this study was to assess whether a treatment policy of prolonged use of corticosteroids in patients with pulmonary sarcoidosis resulted in less long term damage as assessed by symptoms, function, and chest radiography. The general trends in groups $\mathrm{L}$ and $\mathrm{S}$ suggest that this was indeed the case. The data in these two groups have been analysed on the basis of the intention to treat, retaining the original group allocation - that is, group L including the two subjects who did not receive steroids and group $S$ including the six who did. The comparison is therefore between two treatment policies rather than simply an assessment of the long term effects of steroids. We examined whether improvements in patients in group $\mathrm{S}$ were confined to the six patients who received steroids and this appeared not to be the case. Indeed, these individuals showed a greater increase in radiographic $\mathrm{F}$ score between allocation and final assessment than did the remaining 25 individuals $(\mathrm{p}<0.02)$.

The difference between patients in groups $\mathrm{L}$ and $S$ is most clearly evident when the various methods of assessment were combined in a pragmatic "clinical score" (fig 2). Similar trends were seen in each of the functional, clinical, and radiographic indices separately, although only spirometric volumes remained statistically significant when the comparison was made after adjustment for factors at allocation which might have influenced the results.

We estimated that the average improvement in spirometric volumes resulting from long term steroid treatment in this population of patients was $9 \%$ of predicted. Inevitably this was achieved at a certain "cost" related to the treatment. Steroid treatment often proved to be prolonged, even in patients in group $\mathrm{L}$ in whom the treatment had been initiated for reasons other than symptomatic deterioration. The various side effects of treatment were as might have been expected and were seen in approximately two thirds of patients. In only two instances were they sufficiently severe to necessitate discontinuation of treatment, how- 
ever. The anticipated weight gain was seen with a significant difference between groups $\mathrm{L}$ and $S$ in the first year but, interestingly, a significant difference was not sustained at the time of final assessment.

In conclusion, our results in patients with pulmonary sarcoidosis and persistent radiographic shadowing support a small but definite long term advantage from prolonged treatment with corticosteroids. The results also emphasise the need for a period of observation before initiating treatment in those who do not require steroids for symptomatic relief.

The following physicians entered and/or supervised patients in the study:

R A L Agnew
P B Anderson
P Barnes
P Brown
S J Cameron
R M Cayton
J Choo Kang
R A Clark
P A Corris
R J Courtenay-Evans
D Eraut
C C Evans
D H Franklin
J Gaddie
G J Gibson
M Harries
D J Hendrick
A M Hunter
N Keaney
D J Lane
H Lee
D Line
J Lyall
A D Mackay
M F Muers
W Murray
S Nariman
M Partridge
G Petrie
S K Ray
W D Riding
J M Shneerson
H Smyllie
B Stack
A P Tandon
G O Thomas
J Waddell
A K Webb
R F Willey
R S E Wilson

E G Anderson
R H Andrews
B H Bass
W T Berrill
I Campbell
A G Chappell
H W Clague
C K Connolly
S G Cotton
A C Douglas
D A Ellis
K Evans
D C Flenley
R C Godfrey
R Hall
B D W Harrison
N G Hodges
P Jones
S Lal
D G Leaver
R J E Leggett
D J Lipscomb
C McGavin
W G Middleton
I Mungall
C P Mustchin
I C Paterson
S Pearce
N B Pride
H H Rea
J Shaylor
D J Sinclair
J Spencer Jones
J E Stark
A R Tanser
P Turner
J Warren
J Webb
I Williams

The authors also gratefully acknowledge the contributions of JG Scadding and AR Somner who were formerly members of the subcommittee, the secretarial work of Mrs B Wears, and the assistance with data processing of Jin-Hua Mao. Financial support was received from the Chest, Heart and Stroke Association and the British Thoracic Society.

1 Refvem O. Long-term corticosteroid treatment of pulmonary sarcoidosis. In: Iwai K, Hosoda Y, eds. Proceedings of the Sixth International Conference on Sarcoidosis. Balof the Sixth International Conference on Sarcid

2 De Remee RA. The present status of treatment of pulmonary sarcoidosis: a house divided. Chest 1977;71:388-93.

3 Scadding JG. Prognosis of intrathoracic sarcoidosis in England: a review of 136 cases after five years' observation. $B M \mathcal{F}$ 1961;2:1165-72.

4 Colp C. Sarcoidosis: course and treatment. Med Clin North Am 1977;61:1267-78.

5 Israel HL, Fouts DW, Beggs RA. A controlled trial of prednisone treatment of sarcoidosis. Am Rev Respir Dis 1973;107:609-14.

6 Young RL, Harkleroad LE, Lordon RE, Weg JG. Pulmonary sarcoidosis: a prospective evaluation of glucocorticoid therapy. Ann Intern Med 1970;73:207-12.

7 Harkleroad LE, Young RL, Savage PJ, Jenkins DW, Lordon RE. Pulmonary sarcoidosis: long term follow up of the effects of steroid therapy. Chest 1982;82:84-7.

8 Hapke EJ, Meek JC. Steroid treatment in pulmonary sarcoidosis. In: Proceedings of the 5th International Conference on Sarcoidosis. Prague: Universita Karlova, 1969:621-5.

9 Mikami R, Hiraga Y, Iwai K, Kosuda T, Mochizuki H, Homma $\mathrm{H}$, et al. A double-blind controlled trial on the effect of corticosteroid therapy in sarcoidosis. In: Iwai $\mathrm{K}$ Horsoda Y, eds. Proceedings of the 6th International ConHorsoda Y, eds. Proceedings of the 6th International Conference on Sarco

10 Selroos O, Sellergren T-L. Corticosteroid therapy of pulmonary sarcoidosis. Scand f Respir Dis 1979;60:215-21.

11 Yamamoto M, Saito N, Tachibana T, Hiraga Y, Horikawa $\mathrm{M}$, Osada $\mathrm{H}$, et al. Effects of 18 month corticosteroid therapy on stage I and stage II sarcoidosis patients. In: Proceedings of the 9 th International Conference on Sarcoidosis. Proceedings of the 9th Interna

12 Eule H, Weinecke A, Roth I. The possible influence of corticosteroid therapy on the natural course of pulmonary sarcoidosis. Ann NY Acad Sci 1986;465:695-701.

13 Zaki M, Lyons HA, Leilop L, Huang C-T. Corticosteroid therapy in sarcoidosis: a five year controlled follow-up study. N Y State $\mathcal{f}$ Med 1987;87:496-9.

14 Quanjer PH. Standardised lung function testing. Clin Respir Physiol 1983;19(Suppl 5)

15 James DG, Carstairs LS, Trowell J, Sharma OP. Treatment of sarcoidosis. Lancet 1967;ii:526-8.

16 Johns CJ, Zachary JB, Ball WC. A ten year study of corticosteroid treatment for pulmonary sarcoidosis. fohns Hopkins Med 7 1974;134:271-83.

17 Douglas JG, Middleton WG, Gaddie J, Petrie GR, ChooKang YFJ, Prescott RJ, et al. Sarcoidosis: a disorder commoner in non-smokers. Thorax 1986;41:787-91.

18 Harrison BDW, Shaylor JM, Stokes TC, Wilkes AR. Airflow limitation in sarcoidosis - a study of pulmonary function in 107 patients with newly diagnosed disease. Respir Med 1991;85:59-64. 